\title{
LA MUERTE DESIGUAL: TESTAMENTOS BARROCOS EN LA CAPITANÍA GENERAL DE CHILE ${ }^{1}$
}

\author{
The unequal death: Baroques testaments \\ in the General Captaincy of the Kingdom of Chile
}

Luz Ángela Martínez*

\section{RESUMEN}

A partir del orden material y la destinación de los objetos en los Testamentos del s. XVI, este trabajo se aproxima a los primeros imaginarios fúnebres contrarreformistas y barrocos que se instalaron en Capitanía General del Reino de Chile. Tales imaginarios se revisan en los Testamentos de mujeres espańolas, mestizas, encomenderos, mulatos y criollas.

Palabras clave: Colonia chilena s. XVI, barroco, testamentos.

\begin{abstract}
Based on the material order and the destination of the objects in 16th century Testaments, this work approaches the first imagery of counter-reformist and baroque funerals which were held in the General Captaincy of the Kingdom of Chile. Such images are reviewed in the Testaments of Spanish women, mestizas, holders of land grants, mulattoes and creoles.

Keywords: Colonial era in Chile. 16th century, Baroque, Testaments.
\end{abstract}

\footnotetext{
${ }^{1}$ Este artículo es producto del Proyecto No 1100125 del Fondo Nacional de Desarrollo Científico y Tecnológico (FONDECYT), titulado:" Identidad y cultura en el Reino de Chile. Hacia una caracterización de una poética barroca fronteriza”. Todos los testamentos analizados o referidos en este trabajo han sido transcritos por miembros de este proyecto.

* Facultad de Filosofía y Humanidades, Departamento de Literatura, Universidad de Chile. Santiago, Chile. Correo electrónico: luzmartine@gmail.com

Artículo recibido el 13 de septiembre de 2013. Aceptado el 19 de diciembre de 2013.
} 
Lo que sigue forma parte de un proyecto de investigación en curso, centrado en la configuración de los imaginarios y sus representaciones en la cultura barroca del Reino de Chile. En consecuencia, me referiré solamente a algunos testamentos cuyas representaciones nos informan sobre "la manera de ser barroca" en las condiciones geográficas y culturales -a veces inestables- de la frontera ${ }^{2}$ del virreinato del Perú.

Desde el punto de vista del análisis textual, los testamentos chilenos de los siglos XVI y XVII exhiben un fenómeno particular, que tiene que ver, por un lado, con la concomitancia de distintos tipos discursivos y sus fines; y por otro, con las relaciones entre subjetividad y materia. El asunto de interés es que la conjunción de estos órdenes diversos -y la manera en que componen en definitiva el ámbito textual-genera una tensión entre la estructura básica y secular del documento testamentario y el discurso a través del cual la subjetividad aborda, organiza y narra su relación histórica con los objetos.

Si bien el discurso al que me refiero debiera sujetarse a la "cláusula material" y a la escueta retórica judicial que la acompaña, lo que se advierte es que la narración sobre la vicisitud del objeto adquiere supremacía sobre la fórmula y avanza sobre ella disminuyéndola y desajustando de paso la tradición cuasi sacramental del testamento. Lo que esta narración excedida promueve es una tal relevancia de la cosa (res in commerciun) que, por ejemplo, la procedencia y destino de una imagen, su materialidad y hechura, o la procedencia de una camisa, su estado, desgaste, adornos o falta de ellos, adquieren una dimensión discursiva mayúscula, pero francamente conmovedora ante el suceso de la muerte y su más allá. Además de la precariedad humana que esta circunstancia trasluce, lo que hay que resaltar aquí es que el exceso narrativo introduce una notable perturbación en una situación judicial y teológicamente (hiper)normada, en cuanto insufla un hálito de ambigüedad en la inviolable frontera entre el mundo de los objetos y lo supraterreno.

Si bien es cierto que en el acto de testar cruza el ejercicio fuerte de la voluntad en el sentido de "la última" con un "estado de lucidez" que distingue y disgrega los órdenes de la materia, de la existencia y de la trascendencia, no es menos cierto que la "subjetividad testante" , situada en la experiencia de su propia extinción, se enfrenta de manera radical al hecho de que el "Ser" es perecedero frente al orden objetual y percibe que este último no solo lo trasciende sino que, al establecer una suerte de equivalencia de "eternidad" entre el alma y la cosa particular, produce además una "rara" simbiosis entre inmanencia y trascendencia.

En este trance de la subjetividad derrotada por lo que la trasciende (la cosa), el discurso se transforma en la extensión concreta del acto volitivo y en su única manera de permanecer. En consecuencia, el discurso se erige en un instrumento -mixtificador- a través del cual "la voluntad descorporizada" o ausente seguirá actuando desde un lugar

\footnotetext{
${ }^{2}$ El término "frontera" que utilizo aquí refiere a un emplazamiento cultural activo que re-articula las coordenadas cercanía/lejanía respecto de uno o varios centros políticos de la administración virreinal y las productiviza generando una "variación cultural".

${ }^{3}$ Por "subjetividad testante" entiendo un estado específico de la subjetividad: aquella subjetividad que prefigura -por lo tanto, experimenta- la posibilidad de su ausencia del mundo, al mismo tiempo que contempla la posibilidad de una larga existencia en los distintos espacios del "más allá". Y de acuerdo a esta doble prefiguración, elabora el discurso del testamento. Se trata entonces de una subjetividad "en incertidumbre total" para la cual las coordenadas espacio-temporales van perdiendo sentido hasta desvanecerse a favor de las coordenadas imaginativas-discursivas que le permiten, todavía, organizar el mundo. Esto no solo significa que la "subjetividad testante" es una subjetividad eminentemente discursiva, sino, además, que habita sin tiempo en el discurso. Por eso podemos presentizar los testamentos y leerlos como una voluntad $\sin$ desgaste donada al tiempo del mundo.
} 
intermedio entre el "allá y el acá"; lugar desde donde se prevé influirá en dos transcursos invisibles y ajenos a la experiencia: en el devenir del objeto y en el devenir del alma, ya para siempre ajenos al Ser de la experiencia y su "fenecimiento". Hasta donde es posible una comprobación, ese lugar intermedio entre el "allá y el acá" es "el texto del testamento": tal es en definitiva la potencia preformativa (histórica y trascendente) de la palabra testamentaria.

No es de extrañar, entonces, que el discurso narrativo sobre la cosa tome una extensión textual mayor frente a la fórmula testamentaria, la que se reduce o se transforma en una suerte de ordenación siempre sobrepasada por la irrupción más bien caótica del universo objetual. Por eso tampoco extraña que saleros, zarcillos, cucharas, botijas, frazadas, sillas, escritorios, negros, negras, mulatos, mulatas, indios, indias, inscritos por igual en las "cláusulas materiales" del testamento, dejen entrever las rutas por las que han ido y venido de mano en mano en la sociedad colonial chilena, acarreando de paso diferentes formas y grados de valor y apego, y diferentes cargas simbólicas y marcas de poder. En tal sentido, engorrosísimas contabilidades sobre mercancías que se mueven al interior de la Capitanía o entre Santiago y Lima nos informan sobre una "economía de la conciencia", al tiempo que nos interrogan sobre las formas en que la movilidad de los objetos entre el centro y el margen cargan y descargan la conciencia en el ámbito virreinal.

Para hacernos cargo de estos y otros asuntos, así como de la particular relación entre el objeto y el alma en el testamento colonial chileno, es necesario dejar de lado los tópicos de la pobreza -material y espiritual- o la necesidad de la Capitanía, pues ellos suponen de manera falaz que solo las sociedades coloniales opulentas pudieron generar relaciones simbólicas con lo material. $\mathrm{O}$ que solo el objeto suntuoso puede ocupar un lugar en los imaginarios. Para develar las relaciones entre conciencia, cosa y alma en este Reino, parece más productivo un ejercicio que si bien tiene como referentes lo que se ha llamado "La piedad barroca" y la cultura barroca virreinal, no imponga a priori estos conceptos como dos moldes universales explicativos, y se concentre en los fenómenos y particularidades que adquieren esa piedad y cultura en un territorio alejado de los centros coloniales, y más aun de los centros europeos.

Con estos predicamentos, quiero aproximarme al "testamento de Capitanía" y a la "piedad barroca de frontera" comenzando con el comentario de los gestos involucrados en la fundación de la capellanía ${ }^{4}$ de dońa Marina Ortis de Gaete, la viuda de don Pedro de Valdivia, el conquistador de Chile.

Doña Marina realiza su fundación el 16 de diciembre de $1589^{5}$, en la Capilla de la Cofradía de Limpia Concepción y Soledad de Nuestra Señora, en el Convento de Nuestra Señora del Socorro de la Orden Franciscana. Como es de esperarse de su condición social, para este fin aparta rentas e importantes propiedades, entre las que se destaca simbólicamente su casa, puesta en la fundación como cimiento de la futura morada de la memoria y de las

\footnotetext{
${ }^{4}$ En estricto rigor, la Capellanía es un fundación de renta instituida ante un juez con el objetivo de realizar obras pías y con la obligación de decir misas por toda la eternidad a favor del alma de su fundador. En su dimensión simbólica, la Capellanía sirvió para mantener la presencia y prestancia social de las familias más acaudaladas después del fenecimiento de sus miembros. En su dimensión trascendente, mantenía el vínculo de reciprocidad entre los vivos y los muertos, encadenando la salvación de las almas de unos y otros por medio de las rogativas. Ver, Horvitz V., María Eugenia (Dir.), Memoria del nombre y salvación eterna: Los Notables y las Capellanias de misas en Chile 1557-1930. Santiago de Chile: Universidad de Chile. Facultad de Filosofía y Humanidades. Departamento de Ciencias históricas, 2006.

${ }^{5}$ Codicilo, EES, vol. 5, fojas 80v a 83. Testamento, EES, 8, 26-31 v.
} 
rogativas para la salvación del alma. No obstante, en el orden más puramente económico de esta institución religiosa, además de señalar algunos solares que le pertenecen, doña Marina funda su capellanía sobre los dividendos que le reditúan sus actividades de financista de empresas comerciales y de otra actividad muy desarrollada y ejercida tanto por hombres como mujeres en la colonia: la de prestamista. Es así como deja estipulado que se venda al mejor precio en la Capitanía un cargamento de mercaderías que compró a su "costa e riesgo" Gonzalo de Toledo en la ciudad de los reyes, detallando que en la empresa invirtió trecientos treinta pesos de buen oro de contrato. A ese capital y sus ganancias, adiciona otros 710 pesos de oro provenientes de las mismas actividades comerciales, especialmente del préstamo.

Si de una parte la fundación comercial de dońa Marina revela que era una "mujer de negocios" tan moderna como la que más, de otra parte señala una dimensión mixturada bastante más compleja para la mentalidad de la época, en cuanto incorpora el factor de la deuda y lo enlaza a un el ajuste de cuentas que compromete perpetuamente a sus deudores concretos y terrenos con el "más allá" y con la salvación de las almas: la suya y la del conquistador de Chile.

Lo que el gesto fundacional-contrarreformista de doña Marina configura es, en definitiva, una operación que ancla el pago de la deuda al sistema de reciprocidad entre los vivos y los muertos, y a las operaciones que deben realizarse en la tierra para aligerar el paso de las almas por el Purgatorio. Transferida la deuda al financiamiento de la institución perpetua, los deudores contraen la obligación en la trascendencia con las operaciones del "tercer lugar", en donde el Concilio de Trento determinó que se jugaba la salvación de las almas, incluyendo especialmente en este caso, la del deudor.

Si bien el gesto de dońa Marina es replicado por algunos otros sujetos coloniales, el suyo tiene mayores alcances en cuanto no solo implica a sujetos que le son próximos. También destina a su capellanía todos los bienes, haciendas y títulos disputados en un pleito que sostiene con su Majestad el rey (Felipe II) y con los oficiales reales, sus representantes.

El pleito con su Majestad versa específicamente sobre los 3000 pesos inalienables de dote que dońa Marina trajo a su matrimonio con don Pedro y que este invirtió en el Perú y en la empresa de conquista del Reino de Chile. Tres mil pesos con sus ganancias que dońa Marina demanda se le reintegren a costa de la real hacienda, para lo cual "pide y ruega" a los 24 patrones de su capellanía que continúen con el pleito y su causa y las demás diligencias que les parezca después de su muerte y a costa de sus otros bienes.

Si bien dońa Marina se nos presenta como una inversionista de la empresa de conquista que no está dispuesta a que le birlen su capital, aun cuando los afanadores sean su marido, el rey y sus representantes, lo que hay que volver a subrayar es el amarre de la deuda a la capellanía, gesto con el que imbrica el plano de la Historia con el de la trascendencia a través de varios elementos en verdad notables: a) el proceso histórico de la conquista de Chile con el "más allá"; b) a la Corona y su proyecto imperial con el Purgatorio; c) al rey con las operaciones de la salvación o de condenación: en primerísimo lugar, de su propia alma, la de otros y la salvación o condenación del reino.

Todo lo anterior es refrendado por doña Marina en su posterior testamento (1592), en donde nombra a su capellanía como heredera universal de sus bienes, "derechos y acciones”, los que, como dije, mandó defender aun después de su muerte. En cuanto doña Marina no tiene hijos y por lo tanto no está ligando a través de esta institución bienes con linaje, ni descendencia con reciprocidad, bien podríamos leer en esta fundación sobre 
la deuda y el pleito una fuerte recriminación al príncipe, e interpretar la capellanía misma como un instrumento mandatado por la palabra testamentaria para operar en y desde el "acá-más allá, ya sea para hacer justicia en el marco de la historia y en el mundo, o para condenar en la trascendencia a la corona y al imperio; al rey y su alma ${ }^{6}$.

Ciertamente, lo dicho hasta aquí conlleva una afirmación fuerte, en cuanto supone que la capellanía es una institución perpetua de doble anclaje espacio-temporal, cuyo objetivo de salvación de las almas encierra potencialmente su opuesto de condenación, o por lo menos la amenaza certera de que así pueda suceder. En este y otros sentidos, el testamento abre un interesante abanico de posibilidades para observar los imaginarios del más allá, sobre todo cuando es dictado por sujetos nacidos en tierras chilenas, tal como sucede, por ejemplo, con el de la mestiza Águeda Flores (1595) mulato Antón de Guzmán $(1587)^{8}$, todos establecidos ante el escribano Ginés de Toro Mazote.

El de Águeda Flores -famosa por su ascendencia, por sí misma y por su descendencia ${ }^{9}$ - fue dictado con motivo de un viaje a la ciudad de los Reyes, a donde iba a reunirse con su marido. Conforme con sus motivaciones y contexto de producción, este documento no registra los movimientos de una conciencia debilitada por la enfermedad y/o abrazada por la evidencia radical de su muerte. Ajeno a aquellas perturbaciones, lo que muestra el testamento por viaje, en el cual se inscribe el de dońa Águeda, es un ejercicio racional y lucido, en virtud del cual la afirmación de las facultades plenas de la conciencia no puede ser considerada como un lugar común del ítem formulario.

Inspirado por los sentimientos de distancia ${ }^{10}$ y/o ausencia, lo que sí recoge y fija este documento es el movimiento anticipatorio de la muerte y su representación ${ }^{11}$. Es decir, exhibe un acto imaginativo estrechamente vinculado con la mítica relación entre el periplo y la muerte, de manera que el acto de testar se experimenta aquí más como un memento mori que como una experiencia radical de la conciencia ante la posibilidad de su paso al "más allä". En este trance prefigurativo -y por lo tanto teatral- de la muerte imaginada, el sujeto que crea la representación (el mismo que escribe o dicta el testamento) también ocupa el lugar central de la escena, en cuanto que, para elaborar dicho documento, necesariamente debe representarse la situación límite de su propia muerte y representársela a otros, revelando en este proceso lo que piensa en el presente, no lo que pensó en la vida pasada o transcurrida; asimismo muestra cómo concibe, habita y organiza el mundo, no cómo habitó en él. En este sentido, el testamento por viaje exhibe menos un examen desgarrado de la conciencia que una conciencia en el acto de "disponer el mundo" y dispuesta para el mundo.

\footnotetext{
${ }^{6}$ Dońa Marina deja constancia que el rey no solo está vulnerando sus legítimos derechos, sino, además, el testamento del mismo Pedro de Valdivia, quien dejó estipulado cómo debía devolvérsele dicha dote.

${ }^{7}$ EES, 9; f. 200 19-5-1595.

${ }^{8}$ EES, 3 f. 395 a 398.

${ }^{9}$ Águeda es hija de la cacica Elvira de Talagante, de ascendencia inca, y del conquistador alemán Bartolomé Flores. También es la abuela de Catalina de los Ríos y Lisperguer, la famosa Quintrala. Águeda, como su nieta, encarnan la figura de la mujer mestiza poderosa y adinerada, sobre la que se construye la leyenda de la brujería.

${ }^{10}$ Puede parecer extrańo considerar la distancia como un sentimiento profundo, sin embargo, la sensación de "estar lejos de todo" y la experiencia de distintos rangos de distancia, es palpable y determinante en la conciencia de los sujetos del Reino de Chile.

${ }^{11}$ El testamento por viaje se aproxima en muchos aspectos al que realizan quienes toman los hábitos religiosos. El testamento de Fray Antonio Mexia de Mendoza del 1 de octubre de 1595 muestra claramente el acto de representación de la muerte: "he de renunciar este siglo y como si tuviera la muerte presente he de disponer de mis bienes". En este sentido, replica el gesto plástico del sujeto frente a la calavera, tan caro a la sensibilidad barroca.
} 
En este trance anticipatorio e intransitivo hacia el "más allá", y en el proceso de composición de la escena luctuosa que dirige y protagoniza, doña Águeda invoca a la "gloriosa reina de los Ángeles, madre de Dios", a la virgen intercesora "y a los santos y santas de la corte del cielo". Lo que podría pasar desapercibido en esta advocación de fácil mímesis con la tradición o la fórmula religiosa, es la primacía que se otorga a las figuras femeninas y la presencia de un nexo con el "más allâ" en el que parece predominar la confianza en la figura femenina trascendente y en su diligencia para realizar las tareas encomendadas: las preciosas rogativas para la salvación del alma. Este gesto dirigido a lo femenino en el "más allä", tiene su antecedente, correlato y perpetuación en el plano histórico, pues, como bien sabemos, es la ascendencia femenina indígena la que aporta el poder de la riqueza a la familia Flores, de la misma manera que la descendencia femenina de Águeda es la que se erige en la historia chilena en el emblema del poder absoluto.

Como dije, la representación de la muerte imaginada en su anverso revela la conciencia que habita el mundo. Es así como la predominancia de lo femenino en la escena advocatoria tiene su doble material en la escritura en la primera cláusula que doña Águeda destina a las limosnas, en la que deja 50 pesos en "ropa" al monasterio de monjas de la ciudad de Santiago. Lo interesante de este doblaje material es que compone una línea de progresión con la que se engarzan tres niveles jerárquicamente establecidos: uno en la tierra, las monjas; dos en el cielo, las santas y la Virgen. En el primer nivel de esta línea trascendente-matriarcal se instala dońa Águeda y desde ahí organiza, en parte, la dimensión simbólica de su testamento.

Sin que, por supuesto, la presencia femenina pueda considerarse como un elemento que caracteriza en exclusiva la creencia mestiza-criolla, en el caso de esta poderosa encomendera sí alude a uno de los principales acentos del proyecto evangelizador impulsado por el Concilio de Trento y da cuenta de su penetración en la frontera virreinal. Especialmente informa sobre las funciones mediadoras y suplantadoras que se otorgó a la figura femenina trascendente en el sistema de evangelización de las culturas mestizas, a las que "por mezcla de sangres” pertenece doña Águeda, hija de la cacica inca Elvira de Talagante y el conquistador encomendero Bartholomeus Blumenthal, apellido castellanizado en Flores ${ }^{12}$.

En este caso, como en general en las nacientes sociedades mestizas, el "linaje femenino trascendente" seńala por omisión algunas de las principales estrategias desplegadas por las nuevas clases sociales y tipos de sujeto para re-instalarse en el poder después que la conquista destruyera su estructura tradicional en el "nuevo mundo". Se trata del sistema de disimulación-simulación, ocultamiento y mímesis de sustrato teológico que teje lo más medular de las sociedades barrocas indianas y agencia los nuevos mecanismos mestizos de poder. En cuanto el nuevo pensamiento teológico propuso que la Virgen ocupaba simultáneamente los lugares de la madre celeste y terrena ${ }^{13}$, el "linaje femenino trascendente" permite a dońa Águeda disimular su linaje inca y ocultar el lugar de nacimiento mediante la elisión del nombre de su madre. Si se sigue la permanencia

\footnotetext{
${ }^{12}$ En Chile la leyenda de La Tiran legaliza en la trascendencia la unión entre la cacica y/o princesa inca con el conquistador. Básicamente, se trata de la feroz princesa inca, enemiga de los españoles, que se enamora de un portugués y por amor se convierte a la religión del conquistador, traicionando a su pueblo. Hoy la fiesta de la Virgen del Carmen de La Tirana es una de las mayores fiestas religiosas chilenas.

${ }^{13}$ Por supuesto que la virginidad de la Virgen también cubre con su manto la violencia sexual de la conquista. Sobre este punto ya han avanzado diversos estudios.
} 
de este silencio en la disposición de los bienes y tierras, parecería que esta mestiza hereda su inmensa fortuna exclusivamente de su padre, lo que no solo enmascara que la base de la riqueza familiar de los Blumenthal-Flores es totalmente indígena, sino que, además, la pliega a favor de la clase dominante blanca, para que ese pliegue, de absoluto carácter mimético, finalmente entronice el poder mestizo por vía paterna ${ }^{14}$ en el nuevo orden del poder ${ }^{15}$. Finalmente, lo que la elisión materna, el silencio y la simulación de ser el otro encubren, es la transformación del mitimae en encomienda. En este como en otros asuntos, el catolicismo barroco evangelizador entrega las herramientas, instituciones y aval trascendente para la realización de este tipo de enroques, disfraces y doblajes: bien sabemos que el caso de doña Águeda no es el único en que la virgen o la iglesia suplanta eficientemente a la madre.

La presencia y continuidad de un particular tronco femenino proyectado hacia el cielo, pero sostenido en la tierra por las amas mestizas y sus criadas indias, es reforzado por Águeda hasta el final del testamento, en donde estipula que su esclava María y las dos hijas de esta deben servir para siempre a sus propias hijas e impone restricción absoluta a su venta.

El argumento que sustrae a las esclavas de la estricta condición de mercancía se organiza alrededor del hecho de que las esclavas "nacieron en su casa", de modo que "el suelo de la casa” (Ius soli) pareciera operar de una determinada manera jurídico-simbólica en la sociedad colonial, que contiene la capacidad de otorgar al sujeto cobijo y resguardo frente al mundo de lo transable. En la misma perspectiva, "el suelo de la casa" también pareciera tener la capacidad de "negociar" el estatuto del esclavo y de conferir a las indias una condición muy particular -aun sin definir- en el orden social de la esclavitud ${ }^{16}$. Más allá de lo que la restricción de venta puede sugerir acerca de la relación entre las amas mestizas y las esclavas indias (juegos identificatorios de dobles; el doble mestizo de la familia, etc), lo que sí queda claro es que con ella dońa Águeda quiere perpetuar una relación de lealtad entre las unas y las otras, o al menos un sistema de alianzas que a su manera replica lo que ya vimos en el ámbito de las cláusulas espirituales.

En otro aspecto de "la muerte imaginada", si el viaje torna incierto el destino y reposo final de los despojos corporales y hurta con su nebulosa la posibilidad de idear las pompas fúnebres, no ocurre lo mismo con el anuncio del-eventual-deceso a la ciudad; es decir, con los mecanismos de publicación de la noticia de la propia muerte a los habitantes de la urbe. Indiferentemente del lugar donde quede el cadáver, doña Águeda determina que el anuncio debe hacerse en la capital y, más precisamente, en el centro espiritual del Reino de Chile: en la iglesia mayor y en cada uno de los monasterios de la ciudad; en el de San Francisco, Santo Domingo, Nuestra Señora de las Mercedes, San Agustín y en el de la

\footnotetext{
${ }^{14}$ Frente a la nula mención de la madre, en el testamento leemos, en cambio, múltiples y claras marcas de la "mímesis mestiza": "Mando a Juan Rodulfo mi hijo mayor, la vińa y la tierra... esta yo la heredé de mi padre Bartolomé flores...", "Mando a doña María de Flores y nombro por sus bienes que los hubo y heredó de su abuelo mi padre...", "Mando que en las casa de la plaza viva don Juan mi hijo toda su vida y sus herederos a los cuales ruego que no enajenen estas casas por haberlas heredado de mi padre".

${ }^{15}$ Este nuevo orden es el espańol y a él también obedece el cambio de nombre de Bartholomeus Blumenthal.

${ }^{16}$ Por otra parte, numerosos testamento revelan que las esclavas negras o indias quedaban embarazadas en el ámbito de la casa y que, en no pocos casos, los amos y amas sabían quién era el padre de la criatura, de tal manera que la casa era también un lugar en el que se reproducía "el capital de la esclavitud".
} 
Compañía de Jesús, han de decirse cincuenta misas rezadas ${ }^{17}$, con un total de cuatrocientas si adicionamos las cien que dońa Águeda manda a decir por el ánima de sus padres. La disposición apunta a que el anuncio del deceso de esta hija única de cacica y conquistador sea también un acto de conmemoración de sus antepasados y entronización de un linaje: el mestizo -mimetizado al tronco paterno-, que dońa Águeda inaugura en la sociedad chilena y que como tal está decidida a entronizar en el centro espiritual del Reino.

En este sentido, el anuncio de la muerte de esta notable mestiza no puede realizarse solamente en y para la plaza central de la urbe hispánica. Si en el corazón de la Capitanía manda a decir cuatrocientas misas, en el margen manda a los indios de sus encomiendas una enorme cantidad de ovejas, de "ropa" y dinero que han de repartirse durante los cuatro meses posteriores a su fallecimiento "por partes iguales a viejos y mozos de suerte que gocen de esta manda que a cada repartimiento toca y lo coman y vistan sin que entre en poder de protector ni otra persona". Qué duda cabe que parte de la entronización del poder del mestizo en las nacientes sociedades coloniales requiere de esta relación directa y sin mediación de "otro", sostenida a la distancia entre el indio sometido y el "medio indio", en este caso, por el medio blanco. Más allá de los discursos de "pureza de sangre", se trata del establecimiento de la condición mestiza como una a la que aspiran indios y negros en el ascenso social (pero también conquistadores, en cuanto el mestizaje les abría las puertas de la riqueza indígena). Se trata de la (auto)construcción del mestizo como imagen icónica, imantadora, tan propia de la cosmovisión barroca colonial. Doña Águeda es un caso ejemplar de todo lo anterior.

En cuanto el testamento es también un discurso que busca perpetuar el poder a partir de una serie de mecanismos de distinta índole, en el de Águeda debe observarse que el sistema de retribución entre el mestizo y el indio no se establece sobre un supuesto espiritual, ni sobre la realización de ritos religiosos (misas) por el alma de los sirvientes. Se establece a través del "goce de todos" en el tiempo histórico; a través de la comida, la ropa y el dinero, en la órbita de lo terrenal, corporal y carnavalesco. Para la encomienda de indios, cuatro meses de "goce" decreta la mestiza Águeda en conmemoración suya; en la ciudad de los "blancos", cuatrocientas misas.

Volviendo a lo que ha de suceder en la plaza central, se debe atender la destinación de las misas y lo que ese gesto nos puede decir sobre el imaginario barroco que comienza a despuntar en la Capitanía. En la disposición de doña Águeda es notable que las misas de la iglesia mayor las mande a decir directamente por su ánima, en cambio las doscientos cincuenta de los monasterios las manda a decir a "la pasión de Nuestro Sr. Jesucristo y su bendita madre". Esto revela otro de los acentos del imaginario de Trento y del Barroco: aquel que da por sentado que la relación madre-hijo y la pasión que los unifica obrará directa o indirectamente, por reflejo, oblicuamente quizás, a favor del alma del penitente. La sensibilidad, las operaciones metonímicas y formas de representación de doña Águeda, quizá deban ser puestas en relación con la temprana ${ }^{18}$ presencia de la Compañía de Jesús en su testamento, para vislumbrar en esta articulación la rápida penetración de esta orden en la clase alta mestiza chilena y la instalación del imaginario barroco que se encargó de globalizar.

\footnotetext{
${ }^{17}$ La distribución igualitaria de las misas en los distintos monasterios de las órdenes religiosas habla de la competencia entre ellas por captar la devoción de los feligreses, sobre todo de los pertenecientes a las clases altas. En la destinación de dońa Águeda lo novedoso es la inclusión de la orden bastante nueva en la Capitanía, la de los jesuitas.

${ }^{18}$ Los jesuitas llegaron en 1593, el testamento es de 1595.
} 
De manera distinta a dońa Águeda ${ }^{19}$, doña Isabel Nuñez de Herrera sí cumple con la disposición legal que obliga a entregar todos los datos identificatorios del testador, salvo uno. Dice ser residente de la ciudad de Santiago, mujer legítima de Martín de la Cruz, vecino de "la ziudad rrica" (Villarrica), hija legítima de Pedro Nuñez de Herrera y de María López, vecinos de la villa de "badajoz en los Reinos de españa"; más adelante declara ser beata de la orden de san Francisco y agrega ser viuda de Juan Tellez, de quien hereda una encomienda. No obstante esta nutrida ficha identificatoria, doña Isabel no informa sobre su lugar de nacimiento, en circunstancia que su condición de criolla solo puede deducirse del texto del testamento, de la misma manera que el mestizaje de dońa Águeda se sabe por circunstancias históricas distintas de este documento ${ }^{20}$.

Lo interesante del testamento de dońa Isabel es precisamente la doble condición de encomendera y beata relacionada con sus bienes y el territorio geográfico y espiritual del Reino de Chile ${ }^{21}$.

De su encomienda, dońa Isabel busca rescatar una suma bastante modesta para el cumplimiento de ciertas disposiciones que tienen que ver tanto con la expresión de su fe como con vínculos y desplazamientos entre distintas ciudades del Reino. Velada y casada por segunda vez, al parecer en Valdivia, radica ahí la carta de dote por "doze mill y çiento nueve $\mathrm{p}$ [es] os de buen oro" que entrega a su segundo marido, capital del cual demanda la suma de dos mil quinientos para repartirlos entre Santiago y Villarrica. Esto es, entre el centro y el margen político y espiritual del Reino, bajo la forma de rogativas y obras pías.

En el orden que corresponde, manda primero que su cuerpo sea enterrado en el monasterio de san Francisco de la ciudad de Santiago; en ese mismo centro espiritual manda a decir las misas por la salvación de su alma. Luego, sin invocar ni a padres ni esposos, instituye una capellanía para sí misma y otra para "las animas de todos los yn[di]os difuntos que me an seruido". Lo que llama la atención en esta disposición de rogativas por las almas es, sin duda, su sistema de reciprocidad entre vivos y muertos, excéntrico al tradicional tronco familiar de "cristianos viejos" y articulado al margen racial y espiritual de los indios (“¿cristianos nuevos?”). Aun cuando sus disposiciones mantienen las capellanías separadas y deben realizarse después de la muerte en el "más alla’”22, el punto es que esta beata criolla forma una comunidad para la salvación del alma con los subalternos en el margen, pero subvierte ese margen instalándolos con ese mismo acto en el centro espiritual de la capital.

Tal gesto podría leerse de manera aislada, pero se transforma en una orientación (¿espiritual?, ¿social?, ¿̇identitaria?) si se observa la exclusiva focalización de sus limosnas y obras pías. A los mismos indios -vivos y distantes- de la encomienda, destina doscientos

\footnotetext{
${ }^{19}$ Dońa Águeda no da ningún nombre de sus padres, no indica dónde nació y tampoco revela su segundo apellido. Solo indica que es mujer legítima del capitán Pedro Lisperguer, vecino de la ciudad de Santiago.

${ }^{20}$ En general, el lugar de nacimiento constituye una "zona oscura" o velada en los testamentos de sujetos criollos y mestizos del siglo XVI. No así en los testamentos de indios y europeos residentes o vecinos en la Capitanía. Lo que sí se destaca, es la ascendencia cuando esta es de origen europeo. Ahora, se puede pensar que la desaparición del lugar de nacimiento obedece en el caso de las mujeres a que estas pueden identificarse legalmente a partir del marido; sin embargo, en los testamentos de mujeres indias, casadas o no, por lo general se encuentra este dato. El testamento de Isabel de Galvez es ejemplar en este punto (EE.S. volumen: 5, fojas 102 a 103).

${ }^{21}$ Desde otra perspectiva, éste como otros testamentos ofrece una buena visión de la problemática de las mujeres y sus bienes en la Colonia.

${ }^{22}$ En la teología cristiana todas la misas, capellanías, rogativas, etc., tienen como objetivo acelerar el paso de las almas por el Purgatorio, el llamado "tercer lugar" de purificación de las almas en su camino hacia la visión beatífica de Dios.
} 
pesos en comida, vacas y caballos; a una "niña mestiza" que nació en su casa ${ }^{23}$ deja una limosna claramente especificada; a Beatriz yn[di]a y su marido, a Pedro, a Gaspar, a Martín, indios de su servicio, deja también limosnas y vestidos. Manda que "lo principal" de un "senso se distribuya en casar huérfanas pobres que sean virtuosas", de tal suerte que todas sus limosnas van a la misma población de pobres en la comunidad cristiana y de subalternos en la sociedad colonial: indios, indias, mujeres, nińas y mestizos.

En tanto la espiritualidad de dońa Isabel se inscribe en la dualidad centro-margen del territorio del Reino de Chile, es importante observar en el testamento el espejeo entre esos dos polos y el eje cohesivo aportado por la orden franciscana. Si al hospital de Villarrica deja una limosna de veinticuatro pesos en ganado y comida, y a los conventos de san Francisco y santo Domingo de la misma ciudad dona respectivamente las sumas de veinticuatro y diez pesos oro, al convento de san Francisco y al hospital de pobres de Santiago deja también limosnas. Lo único que varía en la réplica centro-margen de este gesto espiritual es la limosna "al monasterio de monjas desta ziudad" (Santiago), a las que pide rueguen por su alma.

Ahora, si examinamos el estatuto de las imágenes en este testamento de beata nos llevamos una sorpresa. Contrariamente de lo que podría esperarse, las imágenes aparecen totalmente desvestidas de cualquier aura propia del culto y son consideradas estrictamente como joyas, o más aun, como moneda de cambio para el pago de deudas:

Ytem: $m[a n]$ ndo se pague a andres de fuenzalida ochenta y çinco $\mathrm{p}$ [es]os y dos $\mathrm{t}$ [omie] $s \mathrm{q}[\mathrm{ue}]$ le deuo en oro desta ziudad el cual tiene unos corales rricos con sus seis estremos de oro llenos de pasta y una cruz de oro y una ymagen de oro esta en el d[ic] ho rrosario y un agnus dey de oro con beriles rromanos pagandole el $\mathrm{d}[\mathrm{c}]$ ho deudo [sic] se cobre del las $\mathrm{d}[\mathrm{ic}]$ has joyas.

Si para doña Isabel las imágenes no tienen otro valor que el material, no sucede lo mismo con el calendario religioso y su régimen de invisibilidad-visibilidad, ausenciapresencia de los seres trascendentes en la tierra. A sus celebraciones ensambla un estrecho programa de misas con el que enlaza la salvación de su alma y la comunidad de los santos.

[...]las quales mysas an de ser en esta manera el dia de la santisima trynidad una misa cantada y otra el dia de la açunçion de n[uest]ra s[eñor]a de la limpia concep[ci]on todas tres cantadas y en la otaua de todos los santos çinco mysas Rezadas y el dia de san josephe una mysa rrezada y otra el dia de santa ana y otra el dia del s[eńo]r san fr[ancis]co y otra mysa Rezada el dia de santa clara y todo el demas rrestante que quedare se diga asimysmo de mysas Rezadas por los frailes de la $\mathrm{d}[\mathrm{ic}]$ a horden del santo o festividad que se rrezare el dia que se hubieren de $\mathrm{d}[\mathrm{eci}] \mathrm{r}$ las $\mathrm{d}[\mathrm{ic}]$ has mysas todas las quales $\mathrm{d}[\mathrm{ic}]$ has mysas asi cantadas como Rezadas se an de d[eic] r en el altar de la capilla de la d[ic]ha cofradía [...].

\footnotetext{
${ }^{23}$ Aquí vuelve a operar la protección de la casa como lugar de nacimiento. Con relación a este mismo espacio, es necesario advertir la diversa configuración familiar de la Colonia chilena. Ahí encontramos "familias" formadas por niños y niñas, indios, mestizos, mulatos, criollos, "entenados", que nacen en las casas o están allegados o encargados en ellas, acerca de los cuales no se da ninguna explicación de procedencia. Junto a esto, amas y amos a veces dejan ver una proximidad familiar significativa con sus esclavas y sirvientes y con los hijos de estos. De tal manera que la casa aparece como un espacio de intenso mestizaje y la familia colonial como el espacio íntimo donde si bien se reproducen todas las relaciones sociales, los lazos afectivos hacen que no se reproduzcan idénticamente sus jerarquías.
} 
La participación en la comunidad de "las animas de todos los yn[di]os difuntos" y la proyección de su propia conmemoración en la de los santos, sin duda nos permite aproximarnos a las configuraciones imaginarias barrocas de una beata en la Capitanía chilena, especialmente en este caso en que la polaridad materialidad/espiritualidad enlazan con la polaridad centro/margen geográfico y social del Reino.

En el testamento del mulato libre Antón de Guzmán, por otra parte, se observa un interesante desbalance entre el relato sobre los objetos y bienes, de un lado, y la fórmula testamentaria y su catálogo de gestos frente a la muerte, de otro. Lo primero que resalta en este testamento es una declaración de fe en la que se reitera insistentemente la adhesión del sujeto a la "yglesia católica de Roma". Tal insistencia refleja el temor ante la posibilidad de que el "demonio enemigo" intervenga en el momento crucial en el que el alma de este cristiano nuevo se desprenda del cuerpo camino al purgatorio. Que esta insistencia exprese la aprensión de Antón o de Ginés de Toro Mazote, el escribano, es algo que no podemos determinar con entera exactitud, pero lo cierto es que la declaración legal en contra del "común enemigo", si bien se encuentra en algunos testamentos redactados por el mismo escribano, de ninguna manera es común a todos. En tal circunstancia podemos pensar que en este caso en especial, en apoyo al "bien morir" y en representación de la comunidad cristiana ${ }^{24}$, el escribano ${ }^{25}$ encontró prudente reforzar la adherencia del cristiano nuevo a la institución religiosa:" para $\mathrm{q}$ [ue] todos juntos Rueguen a dios por my y si el demonio enemigo de n[uest]ra s[an]t a fee catolica al t [iempo] de my muerte o antes me hiziere dudar".

En las disposiciones sobre el cuerpo, en cómo y dónde ha de ser enterrado y en sus cláusulas materiales, el testamento de Antón de Guzmán revela con toda claridad que en la sociedad colonial temprana del Reino de Chile existía una clase de ex-esclavos con oficio, poder económico y en vías de ascenso social. Esta situación se perfila desde la parte identificatoria del testamento, en la cual se omite de quién es hijo y de dónde es natural, y estos dato se suplantan por otro con el que se deja claro a todos cuantos lean ese documento su condición y lugar en la sociedad esclavista de la Colonia: "yo anton de guzmán de color mulato libre q[ue] soi”. En las disposiciones sobre sus despojos mortales también podemos entrever cierta solvencia material, en cuanto manda que el día de su entierro lo acompañe "El cura y sacristán de la yglesia matriz desta çiudad con cruz alta" y, como bien sabemos, la "cruz alta" era privilegio de aquellos que tenían el dinero para pagar esta distinción en sus popas fúnebres. Sin embargo, todo hace pensar que en este caso dicha prerrogativa se dispone pensando menos en el posicionamiento familiar en la sociedad, que en el "realce social del despojo". Anton solo tiene un nieto, dos nietas y una bisnieta, una de las segundas en la lejana Chillán, de tal manera que la "cruz alta" parece un ornato destinado a lucir en medio del acompañamiento que le deben realizar los miembros de la cofradía de la "Redención de cautibos", de la cual es cofrade este excautivo.

\footnotetext{
${ }^{24}$ Por lo general, el uso del plural en la declaración de fe, señala que testador y escribano conforman la comunidad de cristianos ante la muerte.

${ }^{25}$ Señalo directamente al escribano porque es él quien en definitiva fija el texto, tratándose además de uno en el que el testador "no firma porque no sabe". Aun cuando la mención "al común enemigo" es propia de "la declaración de fe" del testamento, como digo, no es una cláusula que Ginés de Toro Mazote introduzca en muchos testamentos del siglo XVI, más bien en pocos. En el de la beata encomendera Isabel Nuñez de Herrera también aparece, pero aquí tampoco se puede afirmar con toda certeza a quién en definitiva pertenece la alusión. Sin embargo, sí se puede poner en relación con la desconfianza que producían las beatas en la sociedad de la época, sobre todo porque su género las hacía presa fácil del demonio.
} 
En relación con la prestancia social de la muerte, es significativo que, del total de las veinte misas que Antón manda a decir, diez de ellas deben realizarse en "la iglesia $\mathrm{m}[\mathrm{a}]$ yor desta ciudad en el altar del s[eñ]or obispo". Si Anton no derrocha su dinero en rogativas u operaciones vinculadas al tránsito del alma por el Purgatorio ${ }^{26}$, la localización que les da sí deja ver que con ellas busca el realce de sus pompas fúnebres, precisamente en el altar del más alto dignatario eclesiástico. Si examinamos esta disposición a la luz de aquella otra en la que manda cruz alta y cura de la "yglesia matriz" de la ciudad, lo que se revela una voluntad de avance desde el anonimato del margen de la esclavitud y el mestizaje hacia la centralidad terrena y visible de la estructura religiosa.

Ciertamente, la cruz alta, el cura de la "yglesia matriz" y el altar del obispo operan para el cadáver y no para el "sujeto vivo". En este sentido podemos precisar que el mecanismo que posibilita y sostiene el ascenso simbólico de Anton mulato en la sociedad colonial es el rito religioso. Más precisamente, lo que permite ese ascenso es la espectacularidad inherente al rito fúnebre del Barroco, entendido y ejecutado como un suceso público: como una representación ${ }^{27}$, cuyo destinatario es la sociedad y su estratificación económica y racial ${ }^{28}$, ante quien se exhibe en definitiva la capacidad de pagar cruz alta y ante quien el sujeto se identifica y afirma en su condición de libertad, como "mulato libre q[ue] soi".

La supremacía del discurso referido a lo material en este testamento se hace evidente si se observa que de los treinta y siete ítems que lo componen solo seis corresponden a disposiciones teológicas, religiosas o rituales. Los restantes treinta y un ítems se refieren a transacciones económicas, principalmente al detalle de todo lo que los vecinos de la ciudad de Santiago adeudan al testador: setecientos treinta y un pesos de oro marcado, más otras cantidades menores de tomíes y ducados.

En este recuento no deja de ser significativo que entre los veinte deudores de Anton se encuentren Diego Muñoz, el escribano de Mendoza, "el tesorero myguel hurt[a]do bera que sea en gloria”, el escribano Alonso del Castillo, el mismo Ginés de Toro Mazote, junto al mulato Ju[an] Fernández, entre otros capitanes y comerciantes. Todos los préstamos respaldados por los más diversos objetos y documentos: cédulas, joyas, vestimenta, imágenes religiosas ${ }^{29}$, cobijas, espadas, espuelas, etc. Ciertamente estos antecedentes económicos permiten pensar que este mulato libre, de oficio sillero y prestamista, debía tener algún poder sobre sujetos que se encontraban por encima suyo en la escala social. Poder que pretende reflejar con la cruz alta y traspasar a su nieto dejándole por herencia las herramientas de su oficio.

$\mathrm{Si}$, en relación con las jerarquías sociales y sus estructuras simbólicas-trascendentes, el testamento de Anton de Guzmán nos permite ver en los gestos y ritos fúnebres una dimensión espectacular de la cual el sujeto subalterno se apropia en su-postrera-voluntad

\footnotetext{
${ }^{26}$ La presencia del Purgatorio en este testamento es casi nula. En él no se manda a decir ninguna misa en memoria de antepasados, conyugue o deudos. Al contrario sucede con la pertenencia del testador a la cofradía de la" Redención de cautibos", a la que le destina un ítem. La ausencia del Purgatorio también contrasta con la marcada presencia del demonio enemigo de n[uest]ra s[an] ta fee catolica".

${ }^{27}$ Véanse las diversas acepciones en el Diccionario de la Real Academia de la Lengua Española.

${ }^{28}$ Todo el rito y las misas en especial, están relacionadas con el pago que se realiza por ellas. De tal manera que la disposición y sus cláusulas sobre el entierro, misas y obras pías, conllevan un enorme aparataje de negociación económica.

${ }^{29}$ Incluso un retablo.
} 
de avance hacia el centro simbólico del poder, en el testamento y codicilo ${ }^{30}$ del castellano Diego Cifontes de Medina se expone ejemplarmente la mentalidad contrarreformista y la espiritualidad tridentina peninsular que recorren el "nuevo mundo" y se instala finalmente en el Reino de Chile. Especialmente aquella dimensión simbólica y modélica hacia la que avanza o quiere avanzar (¿en el más allá?) Anton en el trance de su muerte.

Escrito de su puño y letra, el de Cifontes es un texto considerablemente extenso, establecido con tanto apego a la fórmula testamentaria ${ }^{31}$ como ajeno a su escueta retórica. Profuso en imágenes y giros discursivos, es, en definitiva, un texto generado en el borde de la frontera virreinal, en el cual el imaginario luctuoso del barroco pareciera querer afirmarse en su pleno esplendor.

De manera distinta al mulato Anton de Guzmán o a la mestiza Águeda flores, el peninsular Diego Cifontes (como en general la población indígena proveniente del virreinato del Perú ${ }^{32}$ ) sí entrega todos los antecedentes identificatorios que exige la ordenanza oficial. Dice ser natural de la villa de Cifuentes en los reinos de Castilla, vecino de la ciudad de Cańete de la Frontera y residente de la ciudad de Santiago, datos entre los cuales resalta nombre y procedencia peninsular de padre y madre.

Ya desde la completa identificación, pasando por la numerosa corte celestial que puebla la expositio ${ }^{33}$, en el testamento de don Diego se destacan los acentos, matices y formas que adquiere la fórmula testamentaria modelada por el imaginario religioso tridentino. En este ámbito histórico-cultural, su aura barroca sobresale especialmente por la teatralidad y plasticidad de sus pompas fúnebres, cuya tensión dramática se encuentra en el efecto de contraste que producen sus escuetas disposiciones ${ }^{34}$ versus un exceso notable de espectacularidad ${ }^{35}$ en la ejecución. Por lo mismo su "enterramiento" debió constituir un suceso modélico y digno de imitarse en la sociedad colonial del Reino de Chile.

Lo primero a observar en el diseño de las pompas fúnebres es el preciso manejo del claroscuro barroco ${ }^{36}$, cuyo efecto, en este caso, es el realce de la humildad cristiana con que Diego Cifontes se quiere presentar en su tránsito al "más alla’":

Mando que en mi enterramiento no se haga túmulo, ni se pongan más de doce candelas al tiempo de mi enterramiento y misa de cuerpo presente y que se pongan en cada uno de los altares dos candelas fuera de las doce.

\footnotetext{
${ }^{30}$ Escribanos de Santiago, Vol. 8, fojas 182 a 191 vuelta, 30 de octubre de 1592.

${ }^{31}$ Más apegado a esta fórmula que muchos de los establecidos por Ginés de Toro Mazote, quien practica una notable variación dentro de los márgenes permitidos por la normativa.

${ }^{32}$ Nowack, Kerstin. "Como cristiano que soy: Testamentos de la elite indígena en el Perú del siglo XVI" Indiana 23, 2006, 51-77. Recurso virtual, disponible en: http://www.iai.spk-berlin.de/fileadmin/dokumentenbibliothek/Indiana/ Indiana_23/04Nowack_neu.pdf

${ }^{33}$ La súplica, la meditación sobre la muerte y la declaración de fe.

${ }^{34}$ Por ejemplo, es un enterramiento donde no se contempla la incorporación de la "cruz alta" como símbolo de estatus social. De hecho, la cruz no aparece, ni alta, ni baja.

${ }_{35}$ Por ejemplo: "Ítem. Mando que se digan por mi ánima en la dicha iglesia de Nuestra Seńora del Socorro un novenario de misas rezadas sobre mi sepoltura con sus responsos y se pague de mis bienes la limosna que a mis albaceas les pareciere".

${ }^{36} \mathrm{El}$ juego de las llamas de las velas al interior de las naves oscuras de las iglesias era común a los feligreses de la época. Tal como lo advierte la historiadora Emma de Ramón, todas las representaciones y los ritos realizados al interior de las iglesias deben ser imaginados por nosotros con los efectos que produce ese tipo de iluminación en el entorno y en la sensibilidad de las personas.
} 
En contraste con ese juego de luces y sombras, dispuesto para que la oscuridad enmarque solemnemente la tumba sin túmulo ${ }^{37}$, sigue una disposición que podríamos visualizar como un "instrumento de doble alcance", en cuanto a través de ella don Diego enlaza las rogativas por la salvación de su alma con el funcionamiento y rutina de la ciudad cristiana. Se trata del pedido a todos los religiosos "que al presente se encuentran en la ciudad" para que le digan una misa el día de su muerte. Esta solicitud, vestida de limosna y caridad, apunta, sin embargo, a la centralidad que tenían los oficios religiosos en la rutina diaria de la población colonial, pues a nadie pasa desapercibido que al convocar a todos los religiosos que habitan o están de paso en la ciudad, de paso don Diego convoca (más bien obliga) a todos y cada uno de sus habitantes para que rueguen al menos una vez por su alma. Si a esta citación urbi et orbi sumamos la multitud de santas, santos y arcángeles que don Diego invoca en la expositio, vemos que al interior del escenario claroscuro de la iglesia la multitud visible e invisible componen una segunda escena mortuoria propia del imaginario barroco, cuyo modelo plástico concuerda plenamente con el de El entierro del Conde de Orgaz. Segunda escena que, por supuesto, se organiza alrededor de una primera, cuyo elemento central es la tumba desnuda, sin túmulo.

Ítem pido y ruego en limosna y caridad al señor obispo y prebendados de la sancta iglesia de esta ciudad y a los señores perlados de los conventos del señor Sancto Domingo y San Francisco y de Nuestra Señora de las Mercedes que me hagan limosna y caridad en recompensa de algunos servicios que yo les he hecho que rueguen a Nuestro Señor por mi ánima en sus sacrificios y sufragios $^{38}$ y que cada uno de los dichos señores obispo y prebendados y perlados y religiosos me hagan limosna de decir una misa por mi ánima y asimismo ruego a los demás sacerdotes que al presente se hallaren en esta ciudad al tiempo de mi muerte y a los demás comarcanos me hagan la misma caridad. Ruego a mis albaceas cualquiera de ellos soliciten esta cláusula en rogar y apercibir a los dichos señores susodichos me hagan esta caridad con la mayor brevedad que pudieren y asimismo mando a Mari Diez mi mujer y a mi hijo Gabriel de Cifontes con toda brevedad lo acuerden y soliciten a los dichos mis albaceas o a las personas que mejor lo hagan.

Por la urgencia con que se solicita la multitudinaria rogativa, pareciera que don Diego busca la simultaneidad entre el cielo y la tierra, en virtud de la cual la muerte del sujeto es un suceso que acaece al mismo tiempo en la inmanencia (el mundo; la ciudad) y la trascendencia (el reino de los cielos; la comunidad de los santos; las almas del purgatorio). Por lo mismo, señala la concomitancia de esos dos espacios.

Es interesante observar aquí que si Anton de Guzmán está dispuesto y puede pagar por las misas en el altar del seńor obispo, en lo que hoy podemos llamar "performance de la caridad", este rico castellano pide las multitudinarias misas "de limosna", a la usanza de aquellos testamentos -sobre todo de mujeres- en los que el testador(a) padece de extrema

\footnotetext{
${ }^{37}$ Debe señalarse que esta sepultura es transitoria. Al igual que el alma, de paso por el purgatorio y en "dulce carrera de salvación", el cuerpo de don Diego solo llegará a su destino final cuando se termine de construir la capilla de la cofradía de la Soledad. Mientras tanto, quedará en "depósito" en la iglesia de Nuestra Seńora del Socorro, junto al cuerpo de su primera mujer. Este movimiento de los restos mortales de una capilla a otra no es inusual en una ciudad como Santiago en la que no se han terminado de construir las iglesias. Tampoco en la Capitanía General, en donde las personas que morían fuera y lejos de la capital aspiraban a ser enterradas en el centro espiritual.

${ }^{38}$ De un lado los "servicios" y de otro "las rogativas, sacrificios y sufragios" configuran el sistema de reciprocidad entre los vivos y los muertos en el tránsito por el purgatorio.
} 
pobreza. Tal como otros visten su cadáver con los hábitos de las órdenes a las que nunca pertenecieron, al momento de su muerte don Diego inviste el suyo con la humilde aureola de los despojados de la tierra. En cualquier caso, se debe tener en cuenta que el avance de Anton y la investidura humilde de don Diego, acaecen y se encuentran en el mismo centro simbólico del poder: el altar del obispo. La diferencia entre las rogativas de uno y otro, es que si Anton solo puede acceder a ellas mediante el dinero, para las suyas don Diego apela directamente a los servicios prestados a la jerarquía eclesiástica (a las órdenes religiosas, al obispo) y subraya las recompensas que espera de ella. Esto significa que pone a funcionar en ese mismo nivel y al máximo el sistema de reciprocidad entre los vivos y los muertos.

En relación con las jerarquías sociales simuladas (la de los desamparados) y disimuladas (la dominante) en el testamento de don Diego, resultan significativas las disposiciones sobre los despojos mortales. Sobre el destino inmediato y final de su cadáver don Diego manda, quiere y es su voluntad que:

Ítem Mando que si Dios fuere servido de me llevar de esta presente vida, que mi cuerpo sea sepultado y puesto en depósito en la iglesia de Nuestra Seńora del Socorro que es en el convento y monesterio del Señor San Francisco de esta ciudad en la parte y sepoltura donde esta enterrada Beatriz de Hortigosa, mi primera mujer que sea en gloria hasta en tanto que se acaba la capilla de la cofradía de la Soledad que es en la dicha iglesia donde mando quiero y es mi voluntad que se entierre, en la parte donde mis albaceas, con parecer de los diputados y mayordomos de la dicha cofradía señalaren. Y que el día que pasaren mi cuerpo de la una sepoltura a la otra, se me diga una misa de réquiem como a mis albaceas mejor les pareciere.

Además del traslado del cadáver; es decir, de la situación del "cadáver en tránsito" que en la realidad concreta paradojalmente metaforiza el recorrido del alma desde la tierra al purgatorio y de ahí a la vida eterna, lo que resulta significativo en cualquiera de los dos órdenes es la destinación final: el alma, como dije, a la vida eterna que merece el buen cristiano y el cuerpo a la capilla de la cofradía de la Soledad que congregaba la élite capitalina $^{39}$. Curiosamente, en el avance "hacia el centro" -en este caso, "hacia el centro del centro"- Diego y Anton se encuentran.

En este caso, la dimensión material en este testamento adquiere connotaciones dignas de mención, sobre todo cuando inscribe y permite leer la "mala conciencia" del encomendero tridentino de Frontera:

Ítem. Digo y declaro que soy vecino de la ciudad de Cañete de la Frontera que es en términos de Tucapel como parecerá por las cédulas de encomienda que de ellos tengo de los gobernadores don García Hurtado de Mendoza y de Rodrigo de Quiroga, gobernadores que fueron de este reino".

Ítem. Mando y es mi voluntad que cuando se poblare la ciudad de Cańete de la Frontera donde yo soy vecino y los indios de aquella comarca y de Arauco estuvieren de paz, quietos y pacíficos

\footnotetext{
${ }^{39}$ Pastine Valledor. Amalia La cofradía de nuestra señora de la Soledad. Una aproximación a la espiritualidad del siglo XVIII desde la dimensión material. Recurso virtual, disponible en: http://hdl.handle.net/2250/10520/http://www.cybertesis. uchile.cl/tesis/uchile/2009/pastine_ma/html/index-frames.html

Para revisar la relación entre la élite (poder terreno) y la el poder divino que representan en la tierra la iglesia y las órdenes religiosas remito nuevamente al libro de María Eugenia Hortviz ya citado.
} 
se les den de mi hacienda trescientas ovejas en manera que las puedan haber y gozar por descargo de mi conciencia por cosas que les podré ser a cargo en las malocas que se les hicieron por mi y por mi servicio en el tiempo que andaba en la guerra y yendo caminando por su tierra y para que mejor yo pueda descargar mi conciencia y que todos gocen de la dicha limosna se den las dichas ovejas al hospital de pobres naturales que se fundare en la dicha ciudad de Cañete o Arauco si lo hubiere y si no, como a mi hijo le pareciere que mejor puedo descargar mi conciencia. Las cuales dichas ovejas es mi voluntad las tenga a cargo y en depósito mi hijo, Gabriel de Cifontes como cosa que dejo señalada y apartada para el dicho efecto y pueda gozar y tomar para si y para Francisca Cifontes de Medina, su hermana, el esquilmo y multiplico de las dichas trescientas ovejas hasta que sea tiempo de las entregar a quien cumpla mi voluntad y no sea obligado el dicho mi hijo a dar más ni se le pidan más de las dichas trescientas ovejas porque mi intención no es más de que se de hasta esta cantidad y si mi hijo le pareciere para más descargo de mi conciencia y suya, entregarlas y depositarlas en el hospital de los pobres de esta ciudad de Santiago, lo pueda hacer con las dichas condiciones y con facultad de que las pueda sacar cada y cuando que quisiere y si las entregare al dicho hospital y pobres, gocen del esquilmo y multiplico según dicho es de carneros y lana y el de ovejas hembras goce mi hija Francisca Cifontes de Medina.

Si se revisa esta donación a la luz de lo trascendente o se compara, por ejemplo, con el testamento de doña Isabel Núñez de Herrera, se percibe rápidamente que aquí no se trata de tranzar bienes por misas y dedicarlas a "las animas de todos los yn[di]os difuntos". Dicho con toda claridad: en lo establecido por don Diego no se atisba ningún interés de incorporarse junto con las almas indias en la comunidad de las ánimas del Purgatorio. Por el contrario, lo que salta a la vista es su nula voluntad de establecer con ellas el sistema de reciprocidad tan importante para el cristianismo tridentino. Observadas desde la perspectiva material, las trecientas ovejas tampoco se perciben como una retribución en reconocimiento de "los servicios" prestados por los naturales encomendados. Lo que encontramos aquí es más bien un problema de conciencia y la necesidad urgente, pero engañosa, de descargarla. Pues el verdadero asunto disimulado bajo las vestiduras de la caridad cristiana es el sistemático despojo al pueblo mapuche realizado y/o mandatado ${ }^{40}$ por don Diego en la frontera virreinal. En resumidas cuentas, de lo que sí se trata en este ítem es de limpiar la mala conciencia por las malocas o acciones de guerra, pillaje, robo de ganado, mujeres, tierra, etc. que otros hicieron en su nombre y que este cristiano viejo culposamente percibe como condenatorias y extensivas a su ámbito familiar.

$\mathrm{Si}$, por una parte, don Diego disimula sus problemas de conciencia con la caridad, por otra opera con los mecanismos de la simulación. Basta con leer las condiciones impuestas a la donación para ver en ella una simulación, en cuanto prevé que ninguna de esas ovejas llegará a los indios de la Frontera. La razón es bastante simple: la caridad demanda primero la rendición absoluta de los naturales y un modelo de indio "quieto y pacífico" que encaje positivamente como prueba de la evangelización en el margen de la órbita cristiana, en la cual la conciencia del "buen amo cristiano" requiere -para su absolución- la transfiguración del natural belicoso en el "buen esclavo". Una lectura simple del ítem comprueba que bajo la fórmula del usufructo, lana y ovejas -debidamente separadas en machos y hembras- van desde el principio para su hijo e hija.

Así como este testamento nos permite ver los matices que produce la guerra contra los indios en la conciencia cristiana tridentina, también nos permite observar excepcionalmente

\footnotetext{
${ }^{40}$ Don Diego participa de muchas maneras en esta guerra.
} 
cómo se configura una casa de recogimiento y clausura en la Capitanía de Chile. Lo primero a señalar es que, con mucho beneplácito de su parte, don Diego tiene una hija beata:

Ítem. Mando a Juana mi hija legítima, beata, demás de lo que tengo mandado, todo el ornato de mi oratorio que se entiende dosel y retablos e imágenes y frontales y lo demás del servicio del dicho oratorio y esto el mando por vía de mejora o por aquella forma que más haya lugar en derecho el cual este siempre como estar con la decencia que se requiere.

En relación con a la casa de recogimiento y clausura para las mujeres de su familia, don Diego manda lo siguiente:

Ítem. Que por cuanto entre mi y mi mujer hemos comunicado y de hecho estamos acordados en ello que en las casas de nuestra morada se haga un recogimiento o monesterio con voluntad y licencia del señor obispo y del señor gobernador para que mis hijas Juana, Beatriz y Francisca y Luisa se recojan y encierren debajo de clausura en la dicha casa y en su compañía las que entre mi y ella tenemos acordado digo que si esto no llegare a efecto tan cumplidamente como yo quisiera mando ruego y amonesto a mi mujer, Mari Díaz tenga en recogimiento en la dicha casa a sus hijos con toda la honestidad pusible hasta que tomen el estado que más Dios les encaminare y que si mi hermana Mari Sánchez quisiere recogerse con ellas se le de en mi casa el aposente y parte que ella quisiere y escogiere para su recogimiento y mando a mis hijas y a mi mujer ruego y encargo y amonesto le den el alimento y lo que hubiere menester así de comer y de vestir y todo lo demás necesario y que le tengan el respecto y obediencia mis hijas como a parienta mayor y persona que les desea su bien y mando que no le quiten a la dicha mi mujer ninguna de sus hijas si no fuere con su consentimiento y voluntad de ellas, viviendo virtuosamente.

Si aquí queda en claro cómo se configura el "espacio cerrado" en medio la ciudad y cómo en él convergen la voluntad de las autoridades familiares, civiles y eclesiásticas, también queda clara la necesidad que tiene don Diego de aislar a su familia del mundo en que habita. No solo a su mujer, hermana e hijas, también a su hijo a quien "amarra" a ese proyecto encargándole la tarea de custodiar la clausura familiar en función de "la república".

[...]Y mando a mi hijo, encarecidamente, debajo de la obediencia que debe a su padre que las tenga y ampare para su honra como yo lo haría si presente fuese y si al contrario lo hiciese se lo demande Dios mal y caramente porque debajo de esta confianza irá mi ánima descansada [...].

ítem. Mando a mi hijo, Gabriel de Cifontes y encarecidamente le amonesto y encargo debajo del precepto de la obediencia que Dios manda a los hijos tengan a sus padres que no desampare a su madre ni a sus hermanas mientras su madre viviera y sus hermanas tomen estado que más Dios les encaminare $y$ si yo muriere antes de concluir y hacer de esta casa recogimiento y monesterio para sus hermanas que él con todas calor cristiana procure se cumpla mi voluntad porque en esto hará servicio a Dios y a mi ánima dará mucho contento y que todo lo que pudiere excusar encargarse de ánimas ajenas lo haga pues le queda una pasadia honesta y también viéndole recogido y virtuoso el señor obispo y gobernador que fuere de este reino u los demás que rigen la república le ayudarán con algún entretenimiento con que pueda mejor sustentarse y favorecer a su madre y hermanas pues que (ilegible) que otros que no tienen las partes que él lo hacen ${ }^{41}$.

\footnotetext{
${ }^{41}$ Todas las cursivas de esta cita son mías.
} 
El aislamiento, la clausura, la angustia producida por la disyunción entre la fe del encomendero y la guerra que patrocina, así como los mecanismos de simulación-disimulación y las estructuras imaginarias que le permiten presentizarse en el mundo -junto a Dios- en y desde el más allá, sin duda informan a cerca cómo se configuró la mentalidad barroca del Reino de Chile. Sobre todo en lo que ésta se imbrica con un proyecto hegemónico (hispanizacióncristianización) y se establece como un eje a partir del cual se desprende un abanico de variaciones, tales como las que presentan Anton de Guzmán o Águeda Flores.

Sin duda, las variaciones que presenta el testamento barroco de Capitanía es más amplio que lo revisado hasta aquí, y sin duda ese abanico requiere nuevas perspectivas que faciliten la incorporación del testamento a un campo de análisis que no se centre solamente en el carácter formulario y notarial de las disposiciones testamentarias. En este caso, ensayar un análisis desde la perspectiva del Barroco ha permitido constatar que existen implicancias entre los primeros imaginarios tridentinos asentados en el Reino de Chile y el proceso histórico. Asimismo, ha permitido observar la relevancia de lo materialobjetual y su gravitación en las conciencia de los sujetos que componen la mosaica Colonia chilena. La perspectiva barroca permite sobre todo constatar que aquello de poner mi alma en carrera de salvación implica una serie de elementos en virtud de los cuales la muerte colonial en verdad no igualaba a nadie. $\mathrm{Al}$ menos no en el Reino de Chile.

\section{REFERENCIAS}

Horvitz V., María Eugenia (Dir.), Memoria del nombre y salvación eterna: los Notables y las Capellanias de misas en Chile 1557-1930. Santiago de Chile: Universidad de Chile. Facultad de Filosofía y Humanidades. Departamento de Ciencias históricas, 2006.

Novisima recopilación de las leyes de España: dividida en XII libro en que se reforma la recopilación publicada por el señor don Felipe II en el año de 1567, reimpresa últimamente en el de 1775 y se incorpóranlas pragmáticas, cédulas, decretos, órdenes y resoluciones reales, y otras providencias no recopiladas y expedidas hasta el de 1804; mandada formar por don Carlos IV. Vol. 4, Libro X: De los contratos y obligaciones, testamentos y herencias. París: Librería de Don Vicente Salvá, 1846.

Nowack, Kerstin. "Como cristiano que soy: Testamentos de la elite indígena en el Perú del siglo XVI” Indiana 23, 2006, 51-77. Recurso virtual, disponible en: http://www.iai. spkberlin.de/fileadmin/dokumentenbibliothek/Indiana/Indiana_23/04Nowack_ neu.pdf

Pastine Valledor. Amalia La cofradía de nuestra señora de la Soledad. Una aproximación a la espiritualidad del siglo XVIII desde la dimensión material. Recurso virtual, disponible en:http://hdl.handle.net/2250/10520/http://www.cybertesis.uchile. cl/tesis/uchile/2009/pastine_ma/html/index-frames.html 